\title{
An assessment of the factors affecting the commercialization of cell-based therapeutics: a systematic review protocol
}

David Pettitt ${ }^{1,2}$, Zeeshaan Arshad ${ }^{3,4^{*}}$, Benjamin Davies ${ }^{17}$, James Smith ${ }^{1,5}$, Anna French ${ }^{1}$, Doug Cole ${ }^{6}$, Kim Bure , Sue Dopson ${ }^{8}$, David DiGiusto ${ }^{9}$, Jeff Karp ${ }^{10,11,12}$, Brock Reeve ${ }^{13}$, Richard Barker ${ }^{8}$, Georg Holländer ${ }^{2,14}$ and David Brindley $1,2,8,13,15,16$

\begin{abstract}
Background: Cellular-based therapies represent a platform technology within the rapidly expanding field of regenerative medicine and are distinct from conventional therapeutics-offering a unique approach to managing what were once considered untreatable diseases. Despite a significant increase in basic science activity within the cell therapy arena, alongside a growing portfolio of cell therapy trials and promising investment, the translation of cellular-based therapeutics from "bench to bedside" remains challenging, and the number of industry products available for widespread clinical use remains comparatively low. This systematic review identifies unique intrinsic and extrinsic barriers in the cell-based therapy domain.

Methods/design: Eight electronic databases will be searched, specifically Medline, EMBASE (OvidSP), BIOSIS \& Web of Science, Cochrane Library \& HEED, EconLit (ProQuest), WHOLIS WHO Library Database, PAIS International (ProQuest), and Scopus. Addition to this gray literature was searched by manually reviewing relevant work. All identified articles will be subjected for review by two authors who will decide whether or not each article passes our inclusion/exclusion criteria. Eligible papers will subsequently be reviewed, and key data extracted into a pre-designed data extraction scorecard. An assessment of the perceived impact of broad commercial barriers to the adoption of cell-based therapies will be conducted. These broad categories will include manufacturing, regulation and intellectual property, reimbursement, clinical trials, clinical adoption, ethics, and business models. This will inform further discussion in the review. There is no PROSPERO registration number.

Discussion: Through a systematic search and appraisal of available literature, this review will identify key challenges in the commercialization pathway of cellular-based therapeutics and highlights significant barriers impeding successful clinical adoption. This will aid in creating an adaptable, acceptable, and harmonized approach supported by apposite regulatory frameworks and pertinent expertise throughout the respective stages of the adoption cycle to facilitate the adoption of new products and technologies in the industry.
\end{abstract}

Keywords: Cell-based therapies, Translational medicine, Commercialization, Clinical adoption

\footnotetext{
* Correspondence: za23@st-andrews.ac.uk

${ }^{3}$ University of St. Andrews School of Medicine, University of St. Andrews, St.

Andrews, UK

${ }^{4}$ Docherty Gardens, Glenrothes KY7 5GA, UK

Full list of author information is available at the end of the article
} 


\section{Review background}

As a key constituent of regenerative medicine, cellbased therapies are an exciting platform technology with the prospect of potentially curing what were once considered untreatable diseases [1]. Defined by the BSI (British Standards Institute) as "the therapeutic application of cells regardless of cell type or clinical indication" [2], they present a scientifically, commercially, and clinically important treatment modality. They are distinct from conventional pharmaceuticals, biologics, and medical devices through their capacity to facilitate the de novo production of functional tissue [2] and potential ability to remedy, rather than ameliorate, a spectrum of medical and surgical diseases. Consequently, this has made them attractive to a number of stakeholders, including healthcare practitioners, industry, and investors-all of whom are driving a paradigm shift away from conventional disease management [3].

The cell therapy industry centers on the notion of therapeutically utilizing cells across a multiplicity of disease indications, spanning diverse fields such as neurology, cardiology, and ophthalmology, and extending to both chronic and acute disease states $[4,5]$. Despite its relative infancy, it has successfully established itself as a billion-dollar industry [3, 6], which is projected to grow-supported by an increasing number of marketable products, fiscal investment, and strong M\&A (merger and acquisition) activity [7]. In 2014 alone, venture capital investment into the biotech sector surpassed $\$ 9$ billion (USD) [8] and transformed an industry historically plagued by overly exuberant investments and multibillion-dollar losses [9] into a stable and sustainable market that appears attractive for both future investment and long-term value.

\section{Purpose}

This systematic review will critically examine key challenges in the commercialization pathway of cellular-based therapeutics and highlights significant barriers impeding successful clinical adoption. This will help formulate an adaptable and harmonized approach to commercialization that is aligned with appropriate regulatory frameworks, whilst providing evidence-based recommendations for the adoption cycle. Ultimately, this will help expedite the availability of efficacious medical treatments to patients with high, unmet clinical needs.

\section{Previous reviews and rationale}

Although most cell therapies are currently in pre-launch discovery phases (see Fig. 1), a number of products have achieved success across EU (European Union), US (United States), and global marketplaces. However, despite a promising global demand and favorable investment, the translation of cellular-based therapeutics from "bench to bedside" remains challenging. Difficulties pertaining to healthcare translation are nothing new-the 2006 Cooksey Report [10] identified two major translational gaps in health research, namely translating basic science and clinical research into ideas and products, and subsequently introducing these into clinical practice-both of which are relatable to cell therapies. Translational difficulties, and in particular, the clinical adoption of a therapeutic agent, encompass a complex series of processes and relationships between heterogeneous stakeholder groups.

There are a number of review published that look to assess barriers to the development of cell-based therapies. An example is a study conducted by Dodson et al. (2015), who retrospectively analyzed the development of seven cell-based therapies [11]. They concluded that

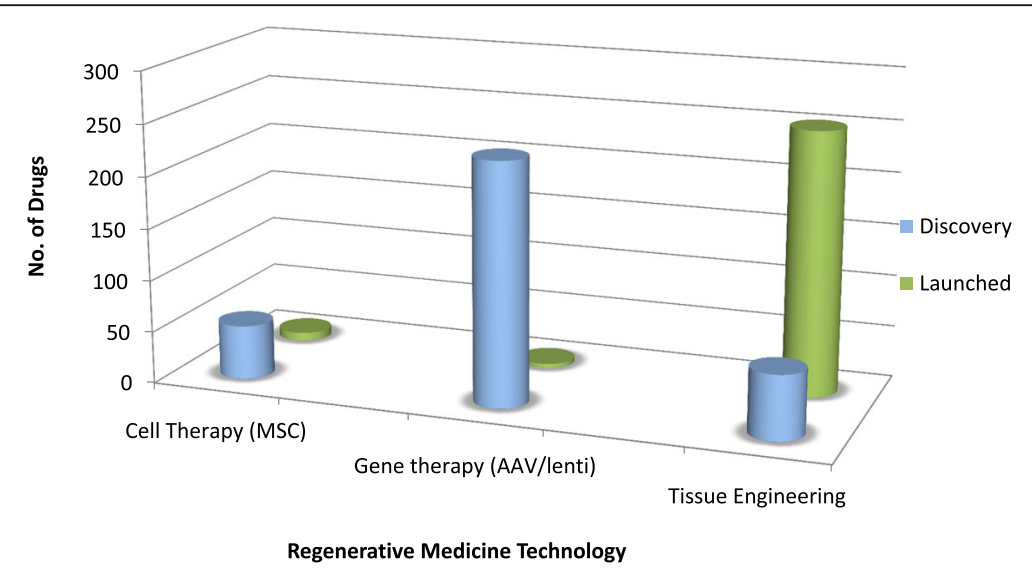

Fig. 1 The current regenerative medicine landscape. Compiled using Thomson Reuters Cortellis ${ }^{T M}$ competitive intelligence software. Gene therapy candidates currently lead the Discovery phase, whilst most Launched drugs comprise tissue-engineered products (including skin substitutes). MSC: mesenchymal stem cell, AAV: adeno-associated virus 
funding, regulation, lack of scientific understanding, reimbursement, and manufacturing are key areas dampening the development of such technology. To the best of our knowledge, however, no systematic evaluation has been conducted to assess the barriers to the commercialization of cell-based therapies. This is a need addressed within this study and is essential to remove bias that may exist when evaluating isolated technologies. Qualitative studies have been previously conducted will also lay the foundation for our pilot data extraction sheet.

\section{Methods/design}

This systematic review will be reported following the Preferred Reporting Items for Systematic Reviews and Meta-Analyses (PRISMA) guidelines [12]. Because this review will only use publically available information, an ethics review board approval will not be required.

\section{Eligibility criteria}

English language manuscripts published within the last 5 years will be included in this review. Inclusion and exclusion criteria to be used are listed in Table 1.

\section{Search strategy and search term development}

A review of the literature will be conducted to identify published studies from the following bibliographic databases: Ovid MEDLINE, Ovid EMBASE, Cochrane Library, EconLit, BIOSIS, WHOLIS, PAIS International, and Scopus. Due to social science work within the area, a manual review of relevant journals will also be carried out.

The search strategy will be developed using keywords and controlled vocabulary terms (e.g., National Library of Medicine's Medical Subject Headings). Additional papers will be obtained through the use of citation-tracking software, pursuing bibliographical references of papers electronically identified in the database searches and through further exploration of gray literature (Tables 2 and 3 ).

Key data regarding electronic database and Thomson Reuters Cortellis ${ }^{\mathrm{Tm}}$ searches is provided below.

The above electronic databases were first accessed on 17 November 2015.

Table 1 Inclusion and exclusion criteria

\begin{tabular}{|c|c|}
\hline Inclusion criteria & Exclusion criteria \\
\hline $\begin{array}{l}\text { - Published within the last } 5 \text { years } \\
\text { - English language publications } \\
\text { - Addressed regenerative medicines } \\
\text { o Autologous or allogeneic } \\
\text { - Identified potential challenges in } \\
\text { the commercialization or clinical } \\
\text { adoption process }\end{array}$ & $\begin{array}{l}\text { - Exclusive focus on manufacturing } \\
\text { - Technical papers examining } \\
\text { isolation techniques, drug delivery } \\
\text { systems or bioprocessing practices } \\
\text { - Non-human or veterinary focus } \\
\text { - Conference abstracts } \\
\text { - Book chapters } \\
\text { - Competing interests-sponsored } \\
\text { by manufacturer }\end{array}$ \\
\hline
\end{tabular}

Table 2 Database search summary

\begin{tabular}{lll}
\hline Database & $\begin{array}{l}\text { Results } \\
(n=)\end{array}$ & $\begin{array}{l}\text { Selected } \\
(n=)\end{array}$ \\
\hline MEDLINE (OvidSP) & 145 & 62 \\
EMBASE (OvidSP) & 1580 & 194 \\
Cochrane Library \& HEED & 104 & 0 \\
EconLit (ProQuest) & 296 & 29 \\
BIOSIS \& Web of Science (Thomson Reuters) & 159 & 37 \\
WHOLIS, WHO Library Database & 12 & 0 \\
PAIS International, ProQuest & 12 & 8 \\
Scopus & 1181 & 147 \\
Gray literature/hand search & - & 31 \\
Subtotal ( $n=)$ & 3489 & 508 \\
Duplicates & $(3520$ inc gray) & \\
Total & & 146 \\
\hline
\end{tabular}

Key words and medical subheadings:

Subheadings: cell therapy; biomedical technology assessment; cost benefit analysis; financial management; economic aspect; commercial phenomena; biological therapy; cell therapy; cost; healthcare cost; stem cell; regenerative medicine

Key words: commercialization; cell therapy; reimbursement; barrier; regenerative medicine

Thomson Reuters Cortellis ${ }^{\mathrm{mi}}$ Competitive Intelligence Software:

This software will be searched to identify cell therapy products from 01/01/2010 to 01/05/2016 (access date: $01 / 05 / 2016)$. Identified products will be stratified by phase, i.e., launched (in market) or in discovery phase.

Key search terms: cell therapy; gene therapy (limited to $A A V$ and lentivirus); mesenchymal stem cell

\section{Study selection}

Two independent reviewers will screen manuscript titles and abstracts for relevance, and full text papers will be obtained for further citations deemed potentially appropriate. Reviewer discrepancies will be discussed until consensus is reached. Full text papers will then be assessed for eligibility according to predefined inclusion and exclusion criteria (as listed in Table 1).

Eligible papers will be subsequently reviewed and key data extracted into a pre-designed data extraction scorecard. An overview of the methodology can be seen in Fig. 2 below:

\section{Synthesis}

The data synthesis and extraction scorecard will be categorized into eight key domains, which are outlined below: 
Table $3 \mathrm{MeSH}$ terms

\begin{tabular}{|c|c|c|c|c|c|}
\hline & Concept 1 & Concept 2 & Concept 3 & Concept 4 & Concept 5 \\
\hline $\begin{array}{l}\text { Subject } \\
\text { heading }\end{array}$ & $\begin{array}{l}\text { Clinical adoption } \\
\text { MeSH: Technology } \\
\text { assessment, Biomedical, } \\
\text { Cost-Benefit Analysis }\end{array}$ & $\begin{array}{l}\text { Cell-based therapeutics } \\
\text { MeSH: Cell- and Tissue-Based } \\
\text { Therapy, MeSH: biological } \\
\text { therapy, MeSH: Regenerative } \\
\text { Medicine }\end{array}$ & $\begin{array}{l}\text { Conventional therapeutics MeSH: } \\
\text { Therapeutics, Drug Therapy, } \\
\text { Enzyme therapy, Molecular } \\
\text { Targeted Therapy, } \\
\text { Immunotherapy, Transplantation, } \\
\text { Monoclonal Antibodies, Vaccines, } \\
\text { biosimilars, small-molecule drugs }\end{array}$ & $\begin{array}{l}\text { Emerging } \\
\text { technologies MeSH: } \\
\text { technology } \\
\text { assessment, } \\
\text { Biomedical, High-Cost } \\
\text { Technology }\end{array}$ & Barriers \\
\hline Keywords & $\begin{array}{l}\text { Clinical adoption, } \\
\text { implementation, } \\
\text { technology assessment, } \\
\text { appraisal, tools, } \\
\text { methodology, } \\
\text { commercialization }\end{array}$ & $\begin{array}{l}\text { Biologics, gene therapy, } \\
\text { regenerative medicines, cell- } \\
\text { and tissue-based therapy, } \\
\text { stem cells, tissue } \\
\text { engineering }\end{array}$ & $\begin{array}{l}\text { Medicines, pharmacological } \\
\text { agents, organ transplant, } \\
\text { monoclonal, vaccine }\end{array}$ & $\begin{array}{l}\text { Translational medical } \\
\text { research }\end{array}$ & \\
\hline
\end{tabular}

1. Manufacturing

2. Regulation and intellectual property

3. Reimbursement

4. Clinical Trials

5. Clinical Adoption

6. Ethics

7. Business models

8. Other

Such domains were identified as being key through brief review of the literature in the area. Each domain will be further subcategorized into important components, e.g., within the Manufacturing domain, subcategories will include Scalability, Automation, and Supply Chain. The tabulated scorecard serves to:

i. Facilitate the assignment of a perceived impact and/ or importance score

ii. Serve as a record of frequency for which a barrier/ domain was mentioned in a manuscript

The data synthesis and extraction scorecard will be piloted on a sample of 23 manuscripts and completed by two independent reviewers. The pilot sample will be acquired from the 83 records identified by stratifying them according to highest impact factor journal $(n=13)$ and

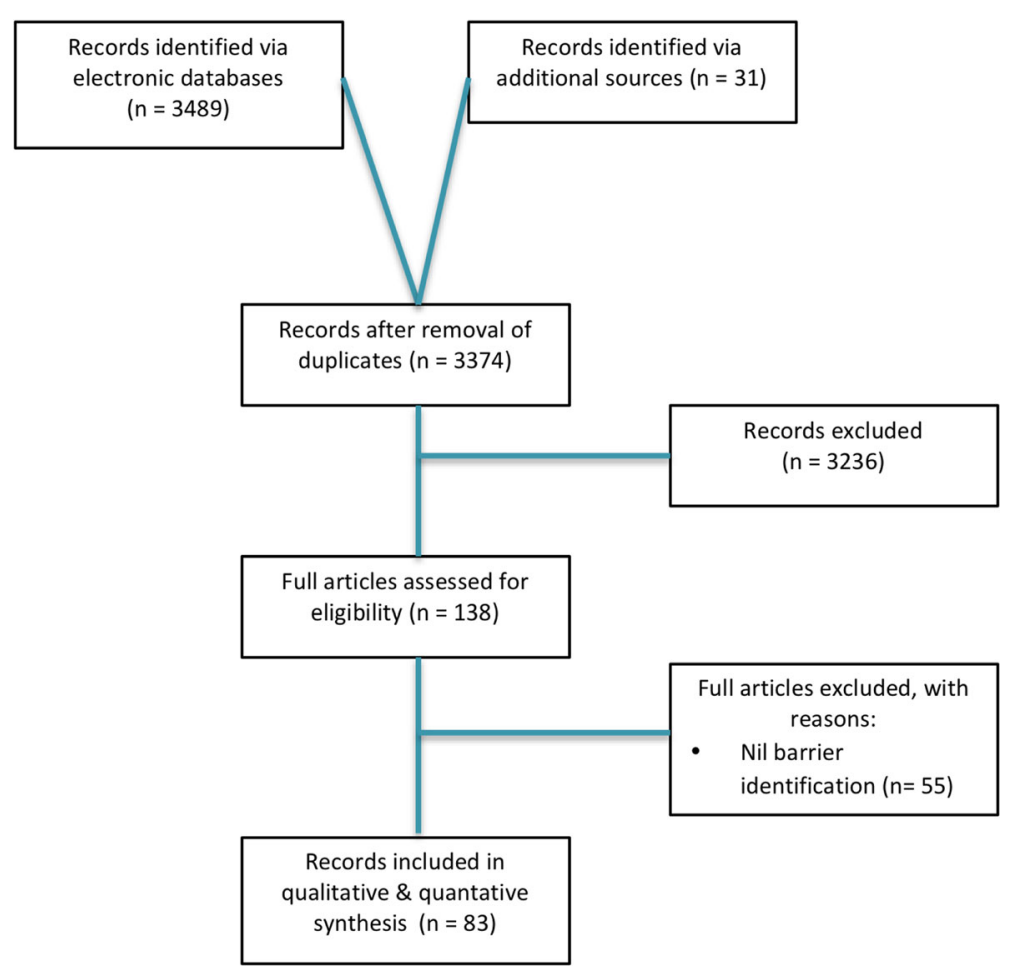

Fig. 2 Systematic review methodological overview 
number of paper citations $(n=10)$. The scorecard will subsequently be applied to all 83 identified records and completed by two independent reviewers. The IRR (inter-rater reliability) will be calculated following analysis.

The data synthesis and extraction scorecard will score each paper on the perceived impact and importance of a cited factor, as seen below in Table 4 .

The excerpt above displays a linear scale ranging from Essential to Negligible, which is accompanied by a numerical value (see parenthesis). The scorecard will also facilitate the documentation of additional information, including publication details (e.g., year, journal, country of publication), cell-based therapy characteristics (e.g., therapeutic indication, autologous vs. allogeneic, cell type), generalizability (e.g., if nature of findings are limited to a particular region by the regulatory system described), and sources of funding and potential conflicts of interest. An additional free text box will be included for "other" challenges or barriers identified in the reviewed manuscripts that did not fall into one of the predetermined domains or subcategories.

A PRISMA-P file is included as Additional file 1. There is no PROSPERO registration number.

\section{Discussion}

This systematic review will critically examine key challenges in the commercialization pathway of cellularbased therapeutics and highlights significant barriers impeding successful clinical adoption. This will help formulate an adaptable and harmonized approach to commercialization that is aligned with appropriate regulatory frameworks, whilst providing evidence-based recommendations for the adoption cycle. Ultimately, this will help expedite the availability of efficacious medical treatments to patients with high, unmet clinical needs.

A number of limitations will be inherent to this study. Notably, the assignment of an impact score is subjective and open to reviewer interpretation. Publication bias is also inherent to the academic literature and it is plausible that more important or challenging commercialization barriers are more widely discussed and, consequently, published. Challenges are also experience-dependent. Cell therapy developers may therefore have a greater degree of real-world experience with the initial phases of commercialization, e.g., manufacturing or seeking regulatory approval with

Table 4 Data synthesis and extraction scorecard excerpt

\begin{tabular}{llll}
\hline Perceived impact and importance & & \\
\hline Essential (4) & Major (3) & Moderate (2) & Negligible (1) \\
Imperative barrier, & High priority, & Lower value & Low priority or \\
definitive & key & or narrower & relevance to field, \\
consideration & consideration & impact & minimal impact \\
\hline
\end{tabular}

demonstrable clinical trial data, in comparison to the latter phases, such as clinical adoption or reimbursement.

Due to the rapid evolution of the regenerative medicine field, it was deemed appropriate to only include papers published in the last 5 years. It is however likely that a number of studies published at the beginning of this period are now outdated. It may also be possible that a number of relevant studies published prior to this time period contain valid arguments for ongoing commercialization challenges and may have been missed. The study was also limited to English language publications, which may have resulted in research findings, particularly from South East Asian nations with novel regulatory mechanisms, being excluded. Such limitations can be mitigated in future research that employs more extensive inclusion criteria and regularly re-visits key literature sources.

\section{Additional file}

Additional file 1: PRISMA-P (Preferred Reporting Items for Systematic review and Meta-Analysis Protocols) 2015 checklist: recommended items to address in a systematic review protocol*. (DOC $81 \mathrm{~kb}$ )

\section{Abbreviations}

IRR: Inter-rater reliability; PRISMA: Preferred Reporting Items for Systematic Reviews and Meta-Analyses

\section{Acknowledgements}

Not applicable

\section{Funding}

We express sincere thanks to the following organizations that have contributed to the CASMI Translational Stem Cell Consortium (CTSCC) as funding and events partners, without whom the consortium and the benefits it will bring to stem cell translation would be constrained: GE Healthcare, the Center for Commercialization of Regenerative Medicine (CCRM), Sartorius Stedim Biotech (formerly TAP Biosystems), Lonza, the California Institute for Regenerative Medicine (CIRM), the Strategies for Engineered Negligible Senescence (SENS) Research Foundation, UK Cell Therapy Catapult, NIH Centre for Regenerative Medicine, the New York Stem Cell Foundation (NYSCF), ThermoFisher Scientific, Eisai, Medipost (US), Medipost (Korea), Celgene, Roche and Oxford Biomedica. Author Brindley gratefully acknowledges personal funding from the Oxford Musculoskeletal National Institute for Health Research (NIHR) the Saïd Foundation, and the SENS Research Foundation. Authors Pettitt and Smith gratefully acknowledge support from the CASMI Translational Stem Cell Consortium (CTSCC).

Funders had no role within the study.

\section{Availability of data and materials \\ The datasets during and/or analyzed during the current study are available from the corresponding author on reasonable request.}

\section{Authors' contributions}

DP was responsible for the study design, data collection/analysis, and draft of the manuscript. BD was responsible for the study design, data collection/ analysis, and draft of the manuscript. JS was responsible for the study design, data collection/analysis, and draft of the manuscript. AF was responsible for the study design, data collection/analysis, and draft of the manuscript. DC was responsible for the study design, data collection/analysis, and draft of the manuscript. KB was responsible for the study design, data collection/ analysis, and draft of the manuscript. SD was responsible for the study design, data collection/analysis, and draft of the manuscript. DD was responsible for the study design, data collection/analysis, and draft of the 
manuscript. JK was responsible for the study design, data collection/analysis, and draft of the manuscript. BR was responsible for the study design, data collection/analysis, and draft of the manuscript. RB was responsible for the study design, data collection/analysis, and draft of the manuscript. All authors read and approved the final version of the manuscript.

\section{Authors' information}

Not applicable

\section{Competing interests}

This article represents the authors' individual opinions and may not necessarily represent the viewpoints of their employers. Brindley is a stockholder in Translation Ventures Ltd. (Charlbury, Oxfordshire, UK) and IP Asset Ventures Ltd. (Oxford, Oxfordshire, UK), companies that among other services provide cell therapy biomanufacturing, regulatory, and financial advice to pharmaceutical clients. Smith is a consultant with IP Asset Ventures Ltd. Brindley also is subject to the CFA Institute's codes, standards, and guidelines, so he must stress that this piece is provided for academic interest only and must not be construed in any way as an investment recommendation. Additionally, at time of publication, Brindley and the organizations with which he is affiliated may or may not have agreed and/or pending funding commitments from the organizations named herein.

\section{Consent for publication}

Not applicable

Ethical approval and consent to participate

Not applicable

\section{Publisher's Note}

Springer Nature remains neutral with regard to jurisdictional claims in published maps and institutional affiliations.

\section{Author details}

${ }^{1}$ The Oxford - UCL Centre for the Advancement of Sustainable Medical Innovation (CASMI), The University of Oxford, Oxford, UK. ²Department of Paediatrics, University of Oxford, Oxford, UK. ${ }^{3}$ University of St. Andrews School of Medicine, University of St. Andrews, St. Andrews, UK. ${ }^{4}$ Docherty Gardens, Glenrothes KY7 5GA, UK. ${ }^{5}$ Nuffield Department of Orthopedics, Rheumatology and Musculoskeletal Sciences, University of Oxford, Oxford, UK. ${ }^{6}$ Flagship Ventures, Cambridge, USA. ${ }^{7}$ Sartorius Stedim, Göttingen, Germany. ${ }^{8}$ Said Business School, University of Oxford, Oxford, UK. ${ }^{9}$ Division of Cell Transplantation and Regenerative Medicine, University of Stanford, Stanford, USA. ${ }^{10}$ Harvard Medical School, Harvard University, Boston, USA. ${ }^{11}$ Brigham and Women's Hospital, Boston, USA. ${ }^{12}$ Harvard-MIT Division of Health Sciences and Technology, Cambridge, USA. ${ }^{13}$ Harvard Stem Cell Institute, Cambridge, USA. ${ }^{14}$ Department of Biomedicine, University of Basel and Basel University Children's Hospital, Basel, Switzerland. ${ }^{15}$ Centre for Behavioral Medicine, UCL School of Pharmacy, University College London, London, UK. ${ }^{16}$ USCF-Stanford Center of Excellence in Regulatory Science and Innovation (CERSI), Stanford, USA. ${ }^{17}$ Orthopedic Surgery Departement, University of Cambridge, Cambridge, UK.

Received: 1 September 2016 Accepted: 9 June 2017

Published online: 26 June 2017

\section{References}

1. Caplan Al, West MD. Progressive Approval: A Proposal for a New Regulatory Pathway for Regenerative Medicine. Stem Cells Transl Med. 2014;3:560-3.

2. Culme-Seymour EJ, Davie NL, Brindley DA, Edwards-Parton S, Mason C. A decade of cell therapy clinical trials (2000-2010). Regen Med. 2012;7:455-62.

3. Mason C, Brindley DA, Culme-Seymour EJ, Davie NL. Cell therapy industry: billion dollar global business with unlimited potential. Regen Med. 2011;6: 265-72.

4. Mount NM, Ward SJ, Kefalas P, Hyllner J. Cell-based therapy technology classifications and translational challenges. Philos Trans R Soc Lond B Biol Sci. 2015:370:20150017.

5. Martell K, Trounson A, Baum E. Stem Cell Therapies in Clinical Trials: Workshop on Best Practices and the Need for Harmonization. Cell Stem Cell. 2010;7:451-4.
6. Brindley DA, Davie NL, Sahlman WA, Bonfiglio GA, Culme-Seymour EJ, Reeve BC, et al. Promising Growth and Investment in the Cell Therapy Industry during the First Quarter of 2012. Cell Stem Cell. 2012;10:492-6.

7. Booth BL. This time may be different. Nat Biotechnol. 2016;34:25-30.

8. Huggett B. Biotech's wellspring - a survey of the health of the private sector in 2014. Nat Biotechnol. 2015;33:470-7.

9. Brindley DA, Reeve BC, Sahlman WA, Bonfiglio GA, Davie NL, CulmeSeymour EJ, et al. The Impact of Market Volatility on the Cell Therapy Industry. Cell Stem Cell. 2011;9:397-401.

10. HM Treasury e-CT. Cooksey Review. http://webarchive.nationalarchives.gov. uk/+/http:/www.hm-treasury.gov.uk/cooksey_review_index.htm. Accessed 8 Aug 2015.

11. Dodson BP, Levine AD. Challenges in the translation and commercialization of cell therapies. BMC Biotechnol. 2015;15:70.

12. Liberati A, Altman DG, Tetzlaff J, Mulrow C, Gøtzsche PC, loannidis JPA, et al. The PRISMA statement for reporting systematic reviews and meta-analyses of studies that evaluate healthcare interventions: explanation and elaboration. BMJ. 2009:339:b2700.

\section{Submit your next manuscript to BioMed Central and we will help you at every step:}

- We accept pre-submission inquiries

- Our selector tool helps you to find the most relevant journal

- We provide round the clock customer support

- Convenient online submission

- Thorough peer review

- Inclusion in PubMed and all major indexing services

- Maximum visibility for your research

Submit your manuscript at www.biomedcentral.com/submit
Biomed Central 